\title{
Stent-graft and double-guiding catheter technique to rescue iatrogenic coronary perforation
}

Ewa Ostrowska, Aleksandra Gąsecka, Tomasz Mazurek, Janusz Kochman

$1^{\text {st }}$ Chair and Department of Cardiology, Medical University of Warsaw, Warsaw, Poland

Submitted: 12 June 2021; Accepted: 29 October 2021

Online publication: 29 October 2021

Arch Med Sci 2021; 17 (6): 1800-1803

DOI: https://doi.org/10.5114/aoms/143151

Copyright $\odot 2021$ Termedia \& Banach

\author{
Corresponding author: \\ Aleksandra Gąsecka MD, PhD \\ $1^{\text {st }}$ Chair and \\ Department of \\ Cardiology \\ Medical University \\ of Warsaw \\ Warsaw, Poland \\ E-mail: gaseckaa@gmail.com
}

\begin{abstract}
Introduction: Coronary artery perforation (CAP) is an infrequent, yet life-threatening complication of percutaneous coronary interventions, posing a major risk of cardiac tamponade and mortality.

Methods: We report on effective management of Ellis type III CAP with use of double-guiding catheter technique and stent-graft implantation.

Results: Prolonged balloon inflation via the first guiding catheter allows for temporary closure of the bleeding site. At the same time, stent-graft is inserted via the second guiding catheter to seal the perforation. After rapid deflation of the balloon, the stent is immediately advanced and expanded. Conclusions: The procedure minimises the time between deflation of the balloon and implantation of the stent-graft, allowing for successful bleeding cessation.
\end{abstract}

Key words: double-guiding catheter technique, stent-graft, coronary perforation.

latrogenic coronary artery perforation is an infrequent, yet dangerous complication of percutaneous coronary interventions $(\mathrm{PCI})$ with the incidence rate ranging from $0.4 \%$ to $5.5 \%$ in case of chronic total occlusion (CTO) $[1,2]$. Risk factors for coronary perforation include advanced age, female sex, CTO, severe calcification and use of rotational atherectomy [2]. Since the perforation poses a major risk of cardiac tamponade and mortality, it should be treated immediately after detection depending on the type (Ellis classification) [3], location and clinical situation. This case report focuses on the application of stent-graft and use of double-guiding catheter technique to manage iatrogenic coronary artery perforation.

Case report. An 82-year-old woman with chronic coronary syndrome was admitted for elective percutaneous coronary intervention (PCI) of a significant stenosis in the left anterior descending (LAD) artery with severe calcifications, without significant lesions in other coronary vessels (Figures $1 \mathrm{~A}, \mathrm{~B}$ ). The patient presented with anginal pain at minimal exertion (Canadian Cardiovascular Society class 3). Medical history included an unsuccessful attempt of PCI of LAD (2019) and permanent atrial fibrillation with percutaneous left atrial appendage closure due to recurrent bleeding episodes. Considering one-vessel disease with low lesion complexity (Syntax score 7) and intermediate risk of perioperative mortality in the EuroScore II (6.67\%), despite the low risk in the STS score (2.73\%), 
the Heart Team opted for percutaneous revascularization. Since the previous $\mathrm{PCl}$ attempt was unsuccessful due to severe calcifications, the use of rotational atherectomy was advocated $[4,5]$.

The procedure was performed through the right femoral access, with the use of 7 French Judkins left guiding 4.5 catheters and BMW guidewire. The rotational atherectomy was conducted with the $1.5 \mathrm{~mm}$ burr at a pace of 160,000 rounds per minute. Subsequently, multiple inflations with non-compliant balloons were performed $(2.75 \times$ $15 \mathrm{~mm}, 3.0 \times 15 \mathrm{~mm}, 3.5 \times 15 \mathrm{~mm}, 3.75 \times 21 \mathrm{~mm})$ at a pressure of 12-20 atmospheres (atm). The final balloon inflation was complicated by the LAD perforation, indicated by contrast extravasation in the middle segment (Ellis type III; Figure $1 \mathrm{C}$ ). This was immediately managed with prolonged balloon inflation $(3.0 \times 15 \mathrm{~mm}, 12 \mathrm{~atm})$ with sub-
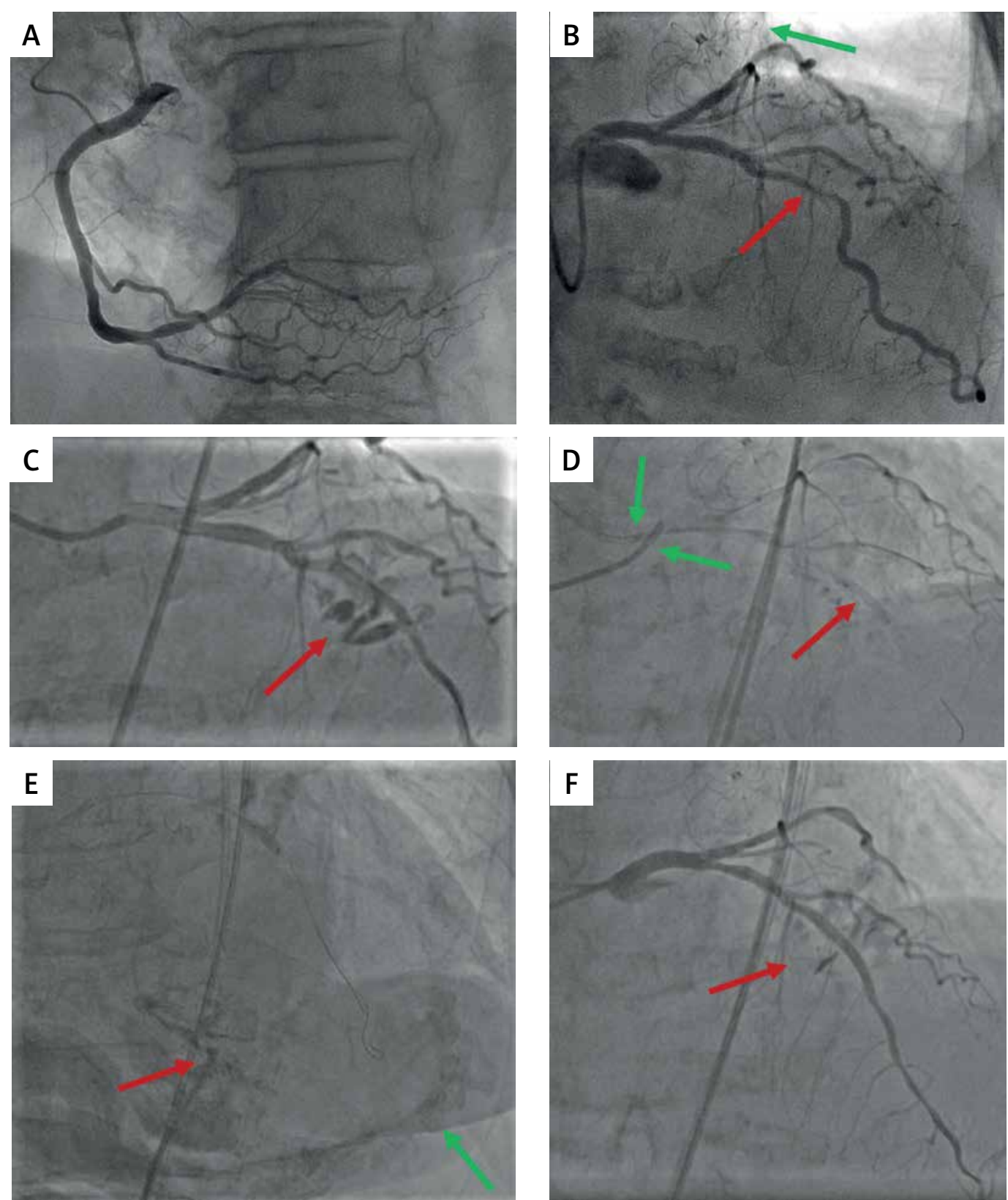

Figure 1. Coronary angiography. A - Right coronary artery without significant atherosclerotic lesions. B - Left coronary artery with a significant, severely calcified stenosis in the middle segment of the left anterior descending artery (LAD; red arrow). A WATCHMAN ${ }^{\mathrm{TM}}$ closure device (Boston Scientific, US) is visible in the left atrial appendage (green arrow). C - Ellis type III LAD perforation, indicated by contrast extravasation in the middle segment. D Double-guiding catheter technique (green arrows) to minimize the time between deflation of a balloon inserted via the first catheter (red arrow) and implantation of a stent-graft. E - Pericardial drain (red arrow) and contrast administration to the pericardium (green arrow) to confirm the right position. $\mathbf{F}-$ Final result of the intervention with minimal contrast extravasation in the middle segment of the stent-graft 
sequent insertion of another guiding catheter to minimize the time between deflation of a balloon inserted via the first catheter and implantation of a stent-graft via the second catheter (double-guiding catheter technique; Figure 2). A stentgraft (PK Papyrus, Biotronik, Germany; $3.0 \times$ $20 \mathrm{~mm}$ at $16 \mathrm{~atm})$ was implanted and post-dilated with $3.0 \times 25 \mathrm{~mm}(16 \mathrm{~atm})$ and $3.5 \times 12 \mathrm{~mm}$ (16 atm) balloons (Figure $1 \mathrm{D})$. Bedside echocardiography showed features of cardiac tamponade, thus an emergency pericardial drainage was executed (Figure $1 \mathrm{E}$ ) with absorption of $700 \mathrm{ml}$ of blood. In addition, dobutamine $(10 \mu \mathrm{g} / \mathrm{kg} / \mathrm{min})$ infusion and intravenous fluid supplementation was started, $50 \mathrm{mg}$ protamine sulfate was administered intravenously for heparin effect reversal and one unit of red blood cells was transfused due to hemoglobin decrease from $9.5 \mathrm{~g} / \mathrm{dl}$ to $7.0 \mathrm{~g} / \mathrm{dl}$ on blood gas analysis. Following stentgraft implantation and pericardial drainage, the control angiography showed minimal extravasation in the middle segment of LAD (Figure $1 \mathrm{~F}$ ).
The patient was hemodynamically stable, with systemic blood pressure of $120 / 60 \mathrm{~mm} \mathrm{Hg}$. The follow-up echocardiography showed no signs of active pericardial effusion and left ventricle ejection fraction of $40 \%$. Laboratory tests revealed a stable hemoglobin value. The patient received dual antiplatelet therapy including acetylsalicylic acid (75 mg once daily) and clopidogrel (75 mg once daily) for 12 months. She was discharged home on postprocedural day 15.

Discussion. A successful PCI requires an appropriate lesion preparation and dilatation, especially in case of severely calcified lesions. Despite the benefits in terms of proper stent implantation, rotational atherectomy and excessive balloon angioplasty increases the risk of coronary artery perforation. The perforation rate with the use of rotational atherectomy during $\mathrm{PCI}$ ranges from $2.1 \%$ [6] to $3.3 \%$ [7]. The alternative techniques include excimer laser coronary atherectomy (ELCA), intravascular lithotripsy and non-atherectomy devices, such as scoring and cutting balloons. The disad-

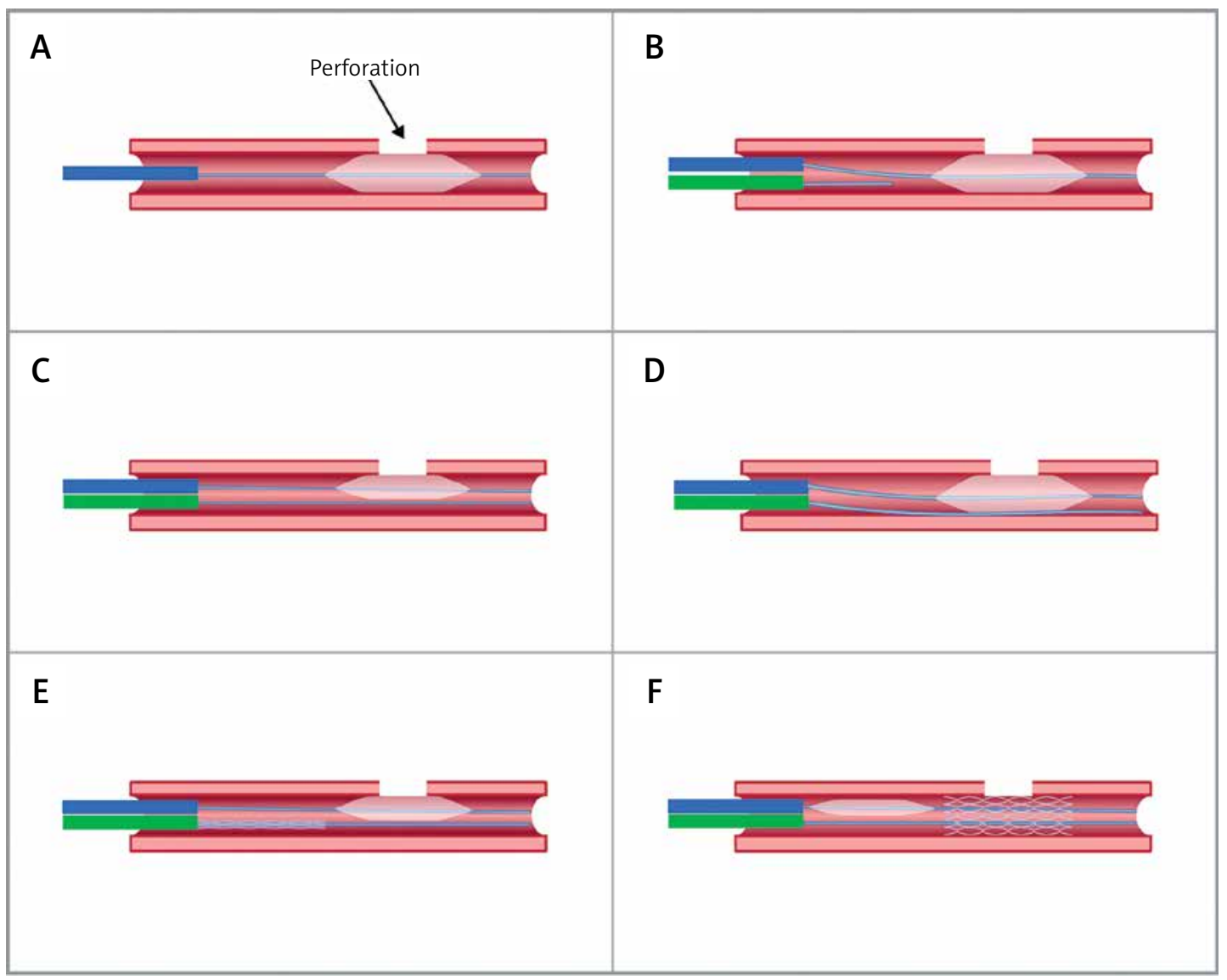

Figure 2. The principle of double-guiding catheter technique to manage iatrogenic coronary artery perforation. A - The initial step, showing prolonged balloon inflation via the first guiding catheter over the perforation (blue color). B - Insertion of another guiding catheter to the ostium of the perforated artery (green color). C - Short deflation of the balloon to promptly insert the second guide-wire to the distal part of the perforated artery. D - Inflation of the balloon to stop the bleeding during the time required for a stent-graft insertion. E - Insertion of a stent-graft via the second catheter. $\mathbf{F}$ - Prompt retraction of the balloon and implantation of the stent-graft to manage the perforation 
vantages of ELCA include limited outcomes in case of heavily calcified lesions. Other techniques are associated with difficulties to deliver the balloons and devices to the target lesion via the torturous and calcified vessels. Hence, rotational atherectomy often remains the technique of choice in similar cases.

The limitation of our procedure is the lack of intravascular imaging data (intravascular ultrasound or optical coherence tomography), which might have increased the safety of our complex $\mathrm{PCl}$ procedure. Although it has not been applied in this specific setting, we highly recommend using intravascular imaging during $\mathrm{PCl}$ of the calcified lesions whenever feasible, to precisely determine the extent and location of the calcifications, the stent expansion and apposition and the potential edge dissections.

If the perforation is not severe (type I or II according to Ellis classification), the prolonged balloon inflation frequently allows for bleeding cessation. However, patients with type III perforation often require stent-graft implantation and pericardial drainage due to cardiac tamponade development. In the described case, the heparin reversal has been used to stop the bleeding and decrease the risk of pericardial tamponade by perforation of the crucial artery (LAD). However, the disadvantages of heparin reversal include the risk of stent-graft thrombosis and clot formation within the pericardium, which makes the percutaneous drainage not feasible. In absence of clear recommendations, we suggest that the decision of heparin reversal is made based on the individual clinical situation and operator's experience.

Double-guiding catheter technique allows to minimize the time between deflation of a balloon inserted via the first catheter and implantation of a stent-graft via the second, as reported by other authors $[8,9]$. In our patient the perforation was caused by repeated balloon inflations, yet in contrast to the previous case report [10], the inflation was preceded by rotational atherectomy. Although the rotational atherectomy did not directly cause the perforation, it might have harmed the vessel. The use of double-guiding catheter technique with stent-graft implantation along with interdisciplinary collaboration between an intervention cardiologist, echocardiographist and cardiac surgeon allowed for successful and prompt management of severe coronary artery perforation, without the need for open-heart surgery.

\section{Conflict of interest}

The authors declare no conflict of interest.

\section{References}

1. Harnek J, James S, Lagerqvist B. Coronary artery perforation and tamponade - incidence, risk factors, predictors and outcomes from 12 years' data of the SCAAR registry. Circ J 2019; 84: 43-53.

2. Azzalini L, Poletti E, Ayoub M, et al. Coronary artery perforation during chronic total occlusion percutaneous coronary intervention: epidemiology, mechanisms, management, and outcomes. Eurolntervention 2019; 15: e804-11.

3. Ellis SG, Ajluni S, Arnold AZ, et al. Increased coronary perforation in the new device era. Incidence, classification, management, and outcome. Circulation 1994; 90: 2725-30.

4. Barbato E, Carrié D, Dardas P, et al.; European Association of Percutaneous Cardiovascular Interventions. European expert consensus on rotational atherectomy. Eurolntervention 2015; 11: 30-6.

5. Neumann FJ, Sousa-Uva M, Ahlsson A, et al.; ESC Scientific Document Group. 2018 ESC/EACTS Guidelines on myocardial revascularization. Eur Heart J 2019; 40: 87-165.

6. Wang YH, Chen WJ, Chen YW, et al. Incidence and mechanisms of coronary perforations during rotational atherectomy in modern practice. J Interv Cardiol 2020; 2020: 1894389.

7. Dippel EJ, Kereiakes DJ, Tramuta DA, et al. Coronary perforation during percutaneous coronary intervention in the era of abciximab platelet glycoprotein IIb/IIla blockade: an algorithm for percutaneous management. Catheter Cardiovasc Interv 2001; 52: 279-86.

8. Rodriguez-Santamarta M, Estevez-Loureiro R, Cuellas C, et al. Double guide catheter technique for sealing an iatrogenic coronary perforation. Res Cardiovasc Med 2016; 5: e31388.

9. Martins-Filho E, Borghi Jr TC, Puzzi MA, et al. Treatment with the double guiding catheter technique for type iii coronary perforation. Rev Brasil Cardiol Invasiva 2013; 21: 401-5.

10. Gupta H, Kaur N, Sharma Y, Lim ST. Modified double guiding catheter 'Ping Pong' technique to treat large coronary perforation: a case report. Eur Heart J Case Rep 2021; 5: ytab173. 